\title{
Pemanfaatan Algoritma Forward Kinematics sebagai Perhitungan Error pada Five Bar Parallel Robot
}

\author{
1,2Ulfah Nadiya *), 1Muhammad Arifin, 2Bagus Prabangkoro, ${ }^{2} \mathrm{M}$ Nibrosul Umam \\ 1UPT Balai Pengembangan Instrumentasi, Lembaga IImu Pengetahuan Indonesia, 2Program Studi Teknik \\ Elektro, Institut Teknologi Bandung \\ ulfahnadiya@gmail.com*)
}

\begin{abstract}
Abstrak
Keakuratan manipulator merupakan ukuran seberapa dekat manipulator dapat mencapai titik tertentu di area kerjanya. Salah satu faktor yang mempengaruhi tingkat keakuratan manipulator ialah error yang dihasilkan dari perhitungan. Belum ada metode yang dapat digunakan untuk melakukan pengukuran tingkat akurasi manipulator secara langsung, diigunakan pendekatan geometri untuk mengetahui keakuratannya. Pada five bar parallel robot, tingkat akurasi dapat dihitung dengan memanfaatkan algoritma forward kinematics. Banyak penelitian yang membuat five bar parallel robot dengan berbagai variasi mode kerja, mode perakitan, dan luas area kerja. Akan tetapi, penelitian tersebut belum mempertimbangkan error yang dihasilkan dari perhitungan invers kinematics. Untuk itu, pada makalah ini dibuat desain five bar parallel robot dengan satu mode kerja, satu mode perakitan, dan memiliki area kerja 300 $\mathrm{mm} \times 300 \mathrm{~mm}$ dengan error komputasi maksimum 0,3 $\mathrm{mm}$. Error dihitung dengan melakukan verifikasi hasil perhitungan invers kinematics menggunakan algoritma forward kinematics. Dengan demikian, area kerja robot yang diperoleh dapat dipastikan tidak memiliki error lebih dari $0,3 \mathrm{~mm}$ secara perhitungan. Dari spesifikasi yang telah ditetapkan tersebut, didapatkan desain robot dengan panjang lengan $\mathrm{L} 1=200 \mathrm{~mm}$ dan $\mathrm{L} 2=230 \mathrm{~mm}$. Dengan mengetahui error komputasi yang dihasilkan oleh manipulator, diharapkan nilai error tersebut dapat dikompensasi dengan konstruksi mekanik yang baik. Kata Kunci: akurasi, five bar parallel robot, invers kinematics, forward kinematics, error.
\end{abstract}

\section{Pendahuluan}

Robot paralel memiliki empat jenis mode kerja dan dua jenis mode perakitan [1]. Kedua hal tersebut merupakan salah satu faktor yang berpengaruh pada daerah kerja yang dapat dicapai oleh five bar parallel robot. Masing - masing daerah kerja robot paralel memiliki perhitungan yang berbeda dan dibatasi oleh kurva singularitas yang berbeda pula. Untuk dapat mengetahui daerah kerja yang dapat dicapai oleh robot, maka robot paralel dimodelkan dengan menggunakan perhitungan kinematika sebagai manipulator pergerakan robot. Terdapat dua jenis perhitungan kinematika, yaitu invers kinematics dan forward kinematics [2]. Dalam hal robotika, kinematika ini dapat dimanfaatkan untuk menghitung hubungan antara end-effector dan sudut sendi. Untuk forward kinematics, sudut sendi menjadi input dalam perhitungan dan outputnya berupa koordinat dari end-effector. Sedangkan invers kinematics merupakan kebalikan dari forward kinematics. Input dari invers kinematics adalah koordinat dari end-effector dan outputnya berupa sudut sendi [3].

Banyak yang telah melakukan penelitian terkait robot paralel dengan berbagai variasi mode kerja dan mode perakitan, kemudian memodelkannya dengan kinematika. Pada [4] melakukan penelitian tentang robot parallel dengan menghilangkan singularitas tipe 1. Dalam desain yang dibuat, singularitas tipe 1 dapat dihilangkan dengan membuat desain robot yang mempunyai empat mode kerja dan satu mode perakitan. Robot yang didesain mempunyai panjang lengan pada tautan distal dan tautan proksimal masing - masing 230 $\mathrm{mm}$. Makalah [5] mengimplementasikan desain yang dibuat oleh [4] dan didapatkan daerah kerja yang relatif luas, yaitu $400 \mathrm{~mm} \times 400 \mathrm{~mm}$. Mitsubishi juga telah membuat robot paralel RP$5 \mathrm{AH}$ [4] yang mempunyai panjang lengan tautan proksimal $200 \mathrm{~mm}$ dan panjang lengan tautan distal $260 \mathrm{~mm}$ dan didapatkan luas daerah kerja sebesar $297 \mathrm{~mm}$ × $210 \mathrm{~mm}$ dengan hanya menggunakan satu mode kerja dan satu mode perakitan. Mecademic [1] juga telah membuat robot paralel dengan panjang lengan tautan distal dan panjang lengan tautan proksimal yang sama, yaitu masing - masing $90 \mathrm{~mm}$. Robot paralel dari Mecademic ini mampu menghilangkan singularitas tipe 1 dan singularitas tipe 2 dan memiliki daerah kerja sebesar $360 \mathrm{~mm}$ x $120 \mathrm{~mm}$. Robot paralel dari Mecademic memiliki empat mode kerja dan dua mode perakitan.

Ketiga robot paralel yang telah disebutkan diatas menggunakan inverse kinematics sebagai perhitungan untuk memodelkan pergerakan robotnya. Akan tetapi, ketiga robot paralel tersebut belum mengimplementasikan perhitungan error pergerakan robot. Error secara komputasi/perhitungan merupakan salah satu faktor yang mempengaruhi tingkat akurasi pergerakan robot [6]. Dan dibandingkan dengan robot serial, robot paralel memiliki tingkat akurasi yang lebih tinggi [7]. Tingkat akurasi yang tinggi diperlukan oleh robot untuk dapat mencapai posisi target dengan tepat. Untuk itu, pada makalah ini akan dibahas mengenai desain five bar parallel 
robot yang memiliki daerah kerja berkisar $300 \mathrm{~mm}$ x $300 \mathrm{~mm}$ dengan satu mode kerja dan satu mode perakitan. Desain robot yang dibuat mempertimbangkan error pergerakan robot dengan memanfaatkan algoritma forward kinematics.

Makalah ini terdiri dari enam bagian. Bagian pertama merupakan pendahuluan yang berisi latar belakang dilakukannya penelitian. Bagian kedua ialah diskusi yang menceritakan tentang desain robot paralel beserta perhitungannya. Terdapat beberapa subbab pada bagian kedua ini. Bagian ketiga merupakan kesimpulan yang berisi kesimpulan dan pekerjaan apa saja yang masih dapat dikembangkan dari penelitian ini. Bagian keempat berisi ucapan terima kasih kepada semua pihak yang telah membantu dalam penelitian ini. Bagian kelima berupa nomenklatur yang berisi daftar simbol beserta penjelasannya. Dan bagian terakhir, yaitu bagian keenam ialah daftar pustaka yang berisi referensi yang digunakan dalam penelitian ini.

\section{Diskusi}

Seperti yang telah disebutkan pada pendahuluan bahwa robot paralel memiliki empat mode kerja dan dua mode perakitan sebagai berikut [1].

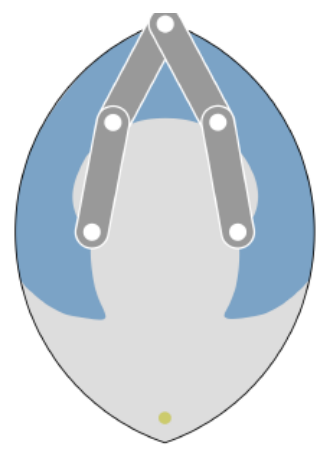

(a) Mode Perakitan +

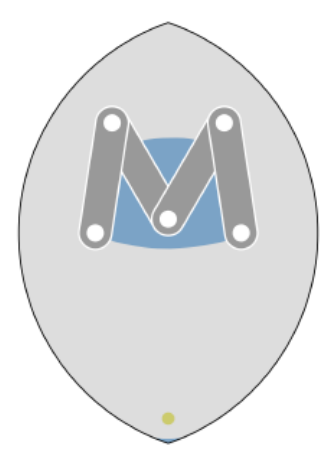

(b) Mode Perakitan -
Gambar 1 mode perakitan five bar parallel robot [1]

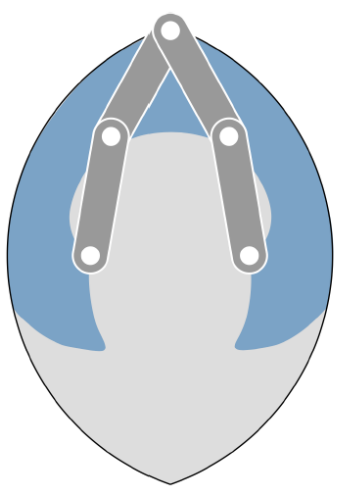

(a) Mode Kerja +-

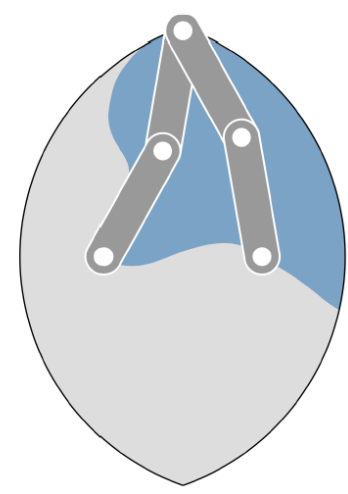

(b) Mode Kerja --

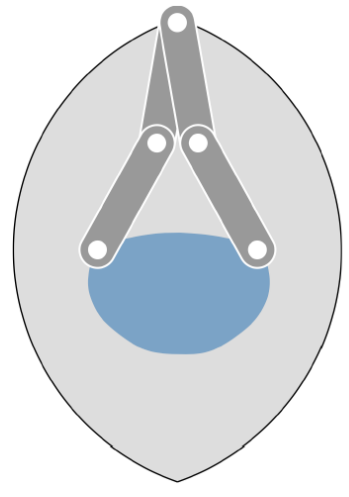

(c) Mode Kerja -+

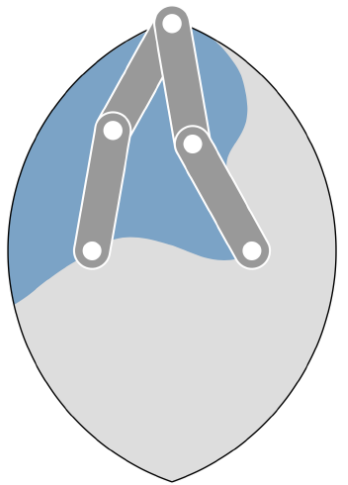

(d) Mode Kerja ++
Gambar 2 mode kerja flve bar parallel robot [1]

Pada makalah ini, pemodelan lengan robot dilakukan dengan menggunakan dua perhitungan kinematika yaitu invers kinematics dan forward kinematics. Invers kinematics digunakan sebagai perhitungan awal, sedangkan forward kinematics digunakan untuk memverifikasi perhitungan yang telah didapatkan dari forward kinematics. Verifikasi diperlukan untuk mengetahui error pergerakan robot.

Pada makalah ini, objektif yang ingin dicapai ialah membuat desain robot yang memiliki daerah kerja $300 \mathrm{~mm}$ x $300 \mathrm{~mm}$ dengan satu mode kerja, yaitu mode kerja +- dan satu mode perakitan, yaitu mode perakitan + . Pada makalah ini ditetapkan nilai error maksimum dengan suatu angka tertentu. Jika perhitungan hasil verifikasi memiliki error lebih dari angka tersebut, maka hasil perhitungan tersebut akan diabaikan dan tidak masuk pada daerah kerja robot. Dengan begitu, maka daerah kerja robot yang terbentuk dapat dipastikan tidak memiliki error lebih dari angka yang telah ditetapkan secara perhitungan.

\subsection{Perhitungan Invers Kinematics}

Algoritma invers kinematics digunakan sebagai algoritma perhitungan pertama karena awalnya diketahui posisi target yang dapat dijadikan sebagai input perhitungan. Dari nilai posisi target tersebut, kemudian diubah menjadi nilai sudut yang harus dilakukan oleh sendi untuk mencapai posisi target yang diinginkan. Perhitungan invers kinematics dihitung secara terpisah untuk masing - masing lengan yang terhubung dengan motor stepper. Dalam kondisi ini masing - masing stepper dimisalkan dengan stepper $\mathrm{x}$ dan stepper y sebagai berikut. 


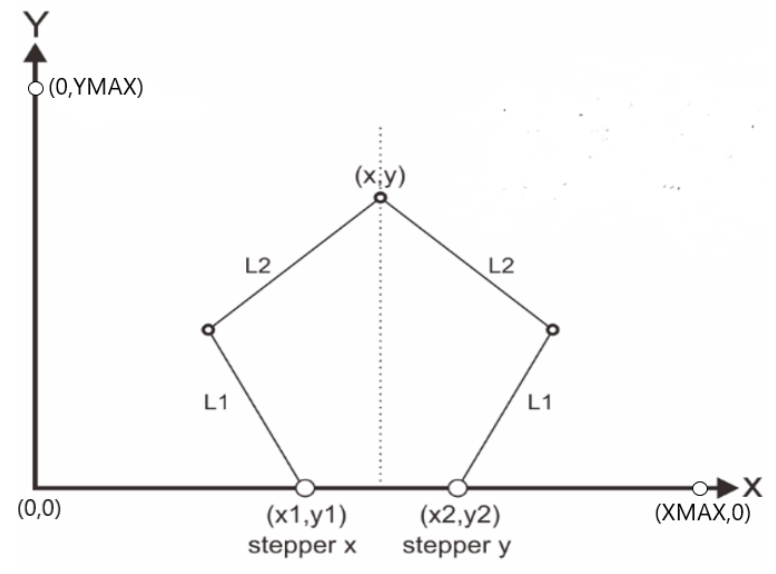

Gambar 3 pemodelan invers kinematics

Perhitungan invers kinematics dilakukan secara terpisah antara stepper $\mathrm{x}$ dan stepper $\mathrm{y}$, sehingga secara terpisah dapat dimodelkan sebagai berikut.

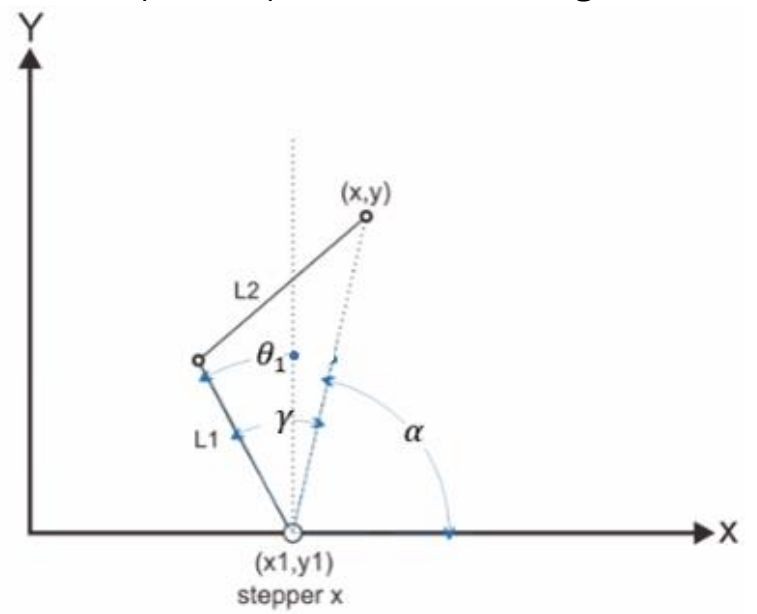

Gambar 4 pemodelan invers kinematics stepper $x$

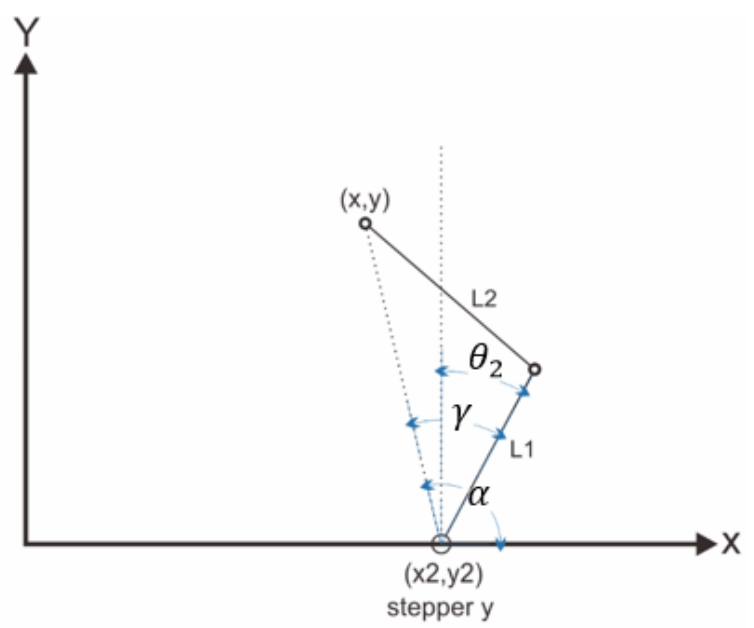

Gambar 5 pemodelan invers kinematics stepper y

Stepper $x$ memiliki persamaan perhitungan perubahan posisi cartesian ke sudut sebagai berikut.

$$
\begin{gathered}
x_{0}=x-x_{1} \\
y_{0}=y-y_{1} \\
\gamma=\cos ^{-1}\left(\frac{l_{1}^{2}-l_{2}^{2}+x_{0}^{2}+y_{0}^{2}}{2 * l_{1} * \sqrt{x_{0}^{2}+y_{0}^{2}}}\right) \\
\alpha=\tan ^{-1}\left(\frac{y_{0}}{x_{0}}\right) \\
\theta_{1}=\alpha+\gamma-90^{\circ}
\end{gathered}
$$

Untuk stepper y memiliki persamaan perhitungan perubahan posisi cartesian ke sudut sebagai berikut.

$$
\begin{gathered}
x_{0}=x-x_{2} \\
y_{0}=y-y_{2} \\
\gamma=\cos ^{-1}\left(\frac{l_{1}^{2}-l_{2}^{2}+x_{0}^{2}+y_{0}^{2}}{2 * l_{1} * \sqrt{x_{0}^{2}+y_{0}^{2}}}\right) \\
\alpha=\tan ^{-1}\left(\frac{y_{0}}{x_{0}}\right) \\
\theta_{2}=\alpha-\gamma-90^{\circ}
\end{gathered}
$$

Pada persamaan (1), (2), (6), dan (7), variabel $x_{0}$ dan $y_{0}$ merupakan jarak antara posisi motor stepper dengan posisi target yang ingin dicapai pada sumbu $x$ dan sumbu $y$. Pada penelitian ini digunakan motor stepper sebagai aktuator dengan resolusi $0.05625^{\circ} /$ step. Karena motor stepper memiliki limitasi pada pergerakan yang dibatasi oleh sudut, maka diperlukan algoritma forward kinematics untuk membandingkan posisi target yang diinginkan dengan posisi target yang dapat dicapai oleh manipulator dengan menggunakan motor stepper tersebut. Nilai $\theta_{1}$ dan $\theta_{2}$ yang didapatkan dari hasil perhitungan invers kinematics kemudian diubah menjadi step yang disesuaikan dengan resolusi motor stepper kemudian diubah lagi menjadi nilai $\theta_{1}$ dan $\theta_{2}$ yang kemudian nilai tersebut menjadi input pada perhitungan forward kinematics.

\subsection{Perhitungan Forward Kinematics}

Forward kinematics digunakan untuk memperkirakan besar error yang dihasilkann dari pergerakan robot. Dengan menggunakan perhitungan forward kinematics maka dapat diketahui posisi target yang tercapai sehingga dapat dihitung besar errornya. Error tersebut dilihat dari perbedaan posisi target yang diinginkan dan posisi yang daapt dicapai oleh robot. Pada penurunan forward kinematics ini, masing - masing motor stepper juga dihitung secara terpisah. Berikut merupakan penuruan persamaan untuk perhitungan forward kinematics. 


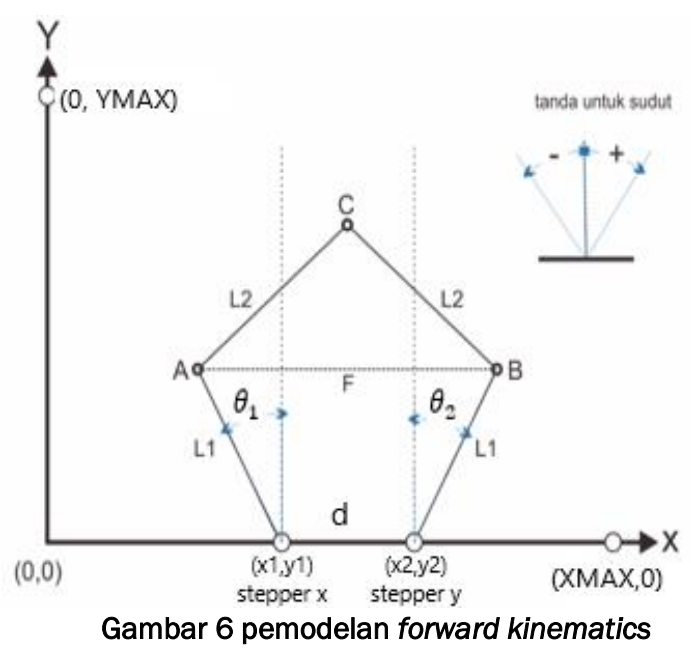

Sudut yang terbentuk pada $\theta_{1}$ dan $\theta_{2}$ masing masing akan bernilai negatif ketika posisi lengan $l_{1}$ berada di kiri sudut $90^{\circ}$ relatif terhadap acuan penggeraknya. Berikut merupakan penurunan persamaan untuk stepper $\mathrm{x}$.

$$
\begin{gathered}
X_{A}=l_{1} * \sin \left(\theta_{1}\right)+x 1 \\
Y_{A}=l_{1} * \cos \left(\theta_{1}\right)+y 1 \\
x 1=\frac{X_{M A X}-X_{M I N}}{2}-\frac{d}{2} \\
y 1=Y_{M I N}
\end{gathered}
$$

Begitu juga untuk stepper y berlaku persamaan sebagai berikut.

$$
\begin{gathered}
X_{B}=l_{1} * \sin \left(\theta_{2}\right)+x 2 \\
Y_{B}=l_{1} * \cos \left(\theta_{2}\right)+y 2 \\
x 2=\frac{X_{M A X}-X_{M I N}}{2}+\frac{d}{2} \\
y 2=Y_{M I N}
\end{gathered}
$$

Kemudian dilakukan peninjauan dari segitiga $A B C$ berikut.
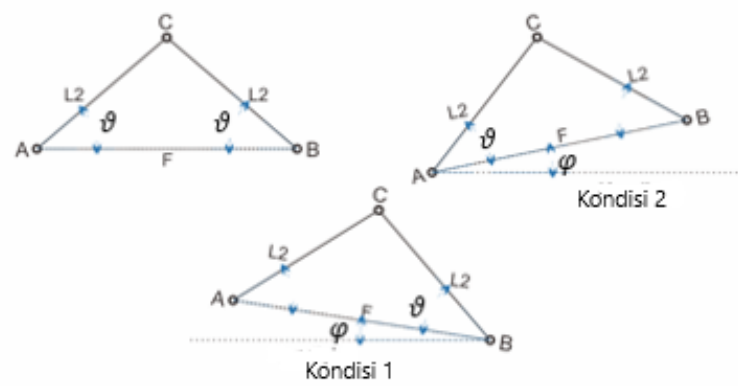

Gambar 7 pemodelan segitiga untuk forward kinematics

$$
\begin{gathered}
F=\sqrt{\left(X_{A}-X_{B}\right)^{2}+\left(Y_{A}-Y_{B}\right)^{2}} \\
\cos \vartheta=\frac{F}{2 * l_{2}} \\
\vartheta=\cos ^{-1} \frac{F}{2 * l_{2}}
\end{gathered}
$$

Dari persamaan (19), maka muncul dua kondisi yang berbeda, yaitu.

a. Kondisi 1: kedudukan $A$ lebih tinggi dari $B$

$$
\begin{gathered}
\varphi=\tan ^{-1}\left(\frac{\left|Y_{A}-Y_{B}\right|}{\left|X_{A}-X_{B}\right|}\right) \\
X_{C}=X_{B}-l_{2} * \cos (\vartheta+\varphi) \\
Y_{C}=Y_{B}+l_{2} * \sin (\vartheta+\varphi)
\end{gathered}
$$

b. Kondisi 2: Kedudukan B lebih tinggi dari A

$$
\begin{gathered}
\varphi=\tan ^{-1}\left(\frac{\left|Y_{A}-Y_{B}\right|}{\left|X_{A}-X_{B}\right|}\right) \\
X_{C}=X_{B}+l_{2} * \cos (\vartheta+\varphi) \\
Y_{C}=Y_{B}+l_{2} * \sin (\vartheta+\varphi)
\end{gathered}
$$

\subsection{Proses Desain}

Setelah dilakukan penurunan perhitunagn invers kinematics dan forwards kinematics pada Subbab 2.1 dan Subbab 2.2, maka dapat dilakukan proses iterasi untuk memperoleh dimensi lengan, jarak antar motor stepper, dan nilai error yang sesuai dengan area kerja yang telah ditentukan. Batasan yang digunakan dalam proses ini ialah

a. Hanya menggunakan satu mode kerja dan satu mode perkaitan yaitu mode kerja +dan mode perakitan + sesuai dengan perhitungan invers kinematics dan forward kinematics yang telah diturunkan sebelumnya.

b. Daerah kerja yang akan dipenuhi sebesar $300 \mathrm{~mm} \times 300 \mathrm{~mm}$.

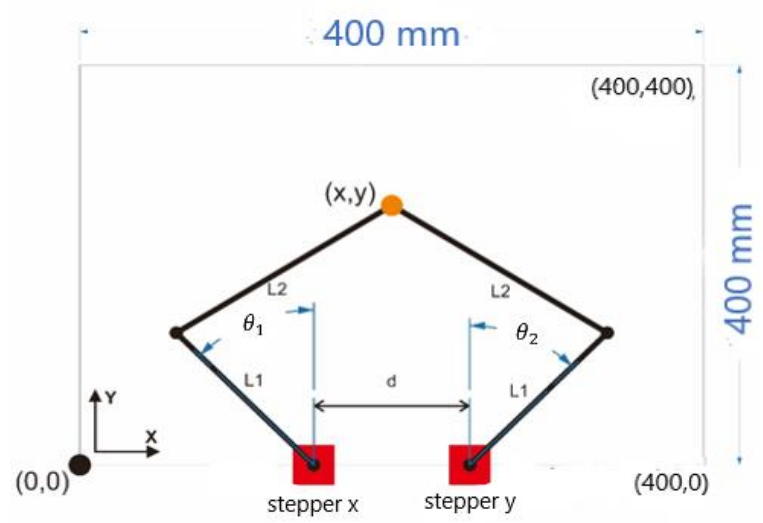

Gambar 8 sistem koordinat five bar parallel robot

$$
\begin{gathered}
X M A X=400 \\
X M I N=0 \\
Y M I N=0 \\
Y M A X=400 \\
\text { spacing =d } \\
x 1=\frac{X M A X}{2}-\frac{d}{2} \\
y 1=Y M I N \\
x 2=\frac{X M A X}{2}+\frac{d}{2}
\end{gathered}
$$




$$
\begin{gathered}
y 2=Y M I N \\
\text { lengan } 1=L 1 \\
\text { lengan } 2=L 2 \\
\text { erroredge }=\text { error }
\end{gathered}
$$

Pada persamaan (28) dan (31) diambil nilai XMAX $=400 \mathrm{~mm}$ dan YMAX $=400 \mathrm{~mm}$, agar spesifikasi area kerja linear $300 \mathrm{~mm}$ x $300 \mathrm{~mm}$ dapat terpenuhi. Setelah dilakukan beberapa kali iterasi dengan menggunakan software Matlab, maka didapatkan panjang lengan yang mampu memenuhi batasan yang telah disebutkan ialah $\mathrm{L} 1$ $=200 \mathrm{~mm}$ dan $\mathrm{L} 2=230 \mathrm{~mm}$, jarak antar motor stepper sebesar $\mathrm{d}=70 \mathrm{~mm}$, dan error edge $=0,3$ $\mathrm{mm}$. Berikut merupakan hasil simulasi yang telah dilakukan menggunakan software Matlab.

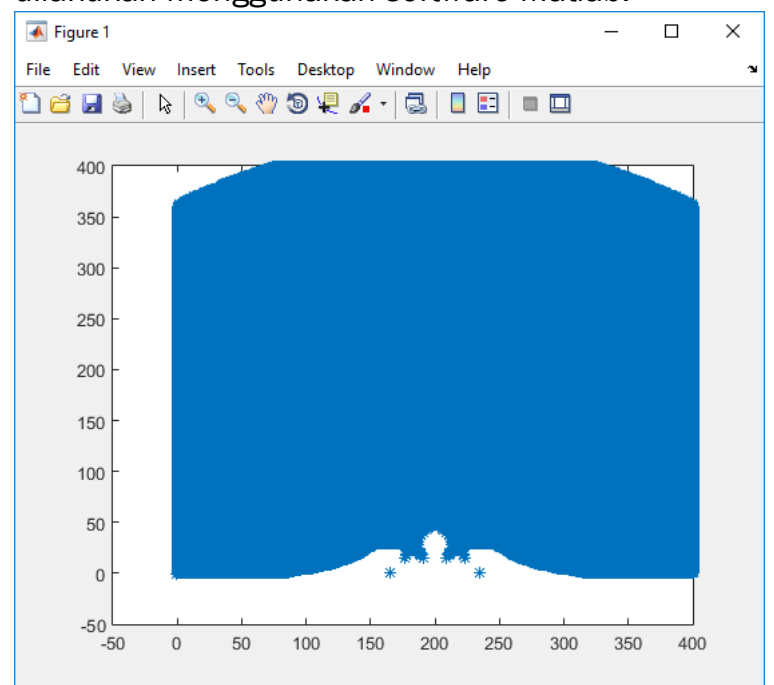

Gambar 9 area kerja five bar parallel robot dengan error $0,3 \mathrm{~mm}$

\section{Kesimpulan}

Forward kinematics merupakan salah satu algoritma kinematika yang dapat dimanfaatkan untuk menghitung error yang dihasilkan dari perhitungan invers kinematics. Dengan memanfaatkan algoritma forward kinematics, maka area kerja robot yang didapatkan pada penelitian ini dapat dipastikan tidak memiliki error lebih dari 0,3 $\mathrm{mm}$ secara komputasi/perhitungan. Dengan mengetahui nilai error hasil komputasi/perhitungan, nilai error tersebut diharapkan mampu dikompensasi menggunakan algoritma komputasi lain atau jika memungkinkan dengan desain konstruksi mekanik yang baik. Selain itu, dengan mengetahui nilai error, maka dapat diketahui posisi yang akan dicapai oleh manipulator sehingga dapat dilakukan pengesetan nilai error yang sesuai dengan kebutuhan dan area kerja yang didapatkan tidak melebihi nilai error maksimum yang telah ditetapkan. Kedepannya, diharapkan adanya penelitian untuk menghitung error manipulator yang mempunyai berbagai macam variasi mode kerja dan mode perakitan sehingga didapatkan manipulator dengan area kerja yang lebih luas.

\section{Ucapan Terima Kasih}

Penelitian ini dibiayai oleh Kelompok Penelitian Teknologi Maju Kontrol Cerdas (Intelligent Control Technology/ICT), UPT Balai Pengembangan Instrumentasi, Lembaga IImu Pengetahuan Indonesia.

\section{Daftar Pustaka}

[1] Mecademic, “Dextar User's Manual Version 1.0,” Mecademic Inc., 2015.

[2] Serdar Kucuk and Z. Bingul, "Robot Kinematics: Forward and Inverse Kinematics," Book of Industrial Robotics: Theory, Modelling, and Control, Kocaeli University, 2006.

[3] Jianxin XU, Wei Wang and Yuan Guang SUN, "Two Optimization Algorithms for Solving Inverse Kinematics with Redundancy," South China, University of Technology and Academy of Mathematics and Systems Science, CAS and Springer-Verlag Berlin Heidelberg, 2010.

[4] Alexandre Figielski, Ilian A. Bonev, and Pascal Bigras, "Towards Development of a 2-DOF Planar Parallel Robot with Optimal Workspace Use," IEEE International Conference on Systems, Man and Cybernetics, Canada, pp 1562-1566, January 2008.

[5] Francis Bourbonnais and Ilian Bonev, "Development of a Five-Bar Parallel Robot with Large Workspace," Proceedings of the ASME, International Design Engineering Technical Conferences and Computers and Information in Engineering Conference (IDETC/CIE), Canada, August 2010.

[6] Zoran Pandilov and Vladimir Dukovski, "Comparison of the Characteristics between Serial and Parallel Robots," Bulletin of Engineering, Acta Tehnica Corviniensis, Tome VII, 2014.

[7] Zhao Xin-hua, et al.. "Kinematic Modeling and Error Analysis of the Six Pole Parallel Robot," IEEE Advanced Information Management, Communicates, Electronic and Automation Control Conference (IMCEC), China, pp 13991402, China, October 2016. 